\section{PWE-113 HAEMOSTASIS EXPERIENCE ON COMPLETION OF SPECIALIST TRAINING IN GASTROENTEROLOGY: ANALYSIS OF THE JETS E-PORTFOLIO}

\footnotetext{
1,2Keith Siau** ${ }^{*}$ Allan J Morris, ${ }^{4}$ Aravinth Murugananthan, ${ }^{4}$ Brian C McKaig, ${ }^{5}$ Paul Dunckley. ${ }^{1}$ Joint Advisory Group, London; ${ }^{2}$ University of Birmingham, Birmingham; ${ }^{3}$ Glasgow Royal Infirmary, Glasgow; ${ }^{4}$ New Cross Hospital, Wolverhampton; ${ }^{5}$ Gloucester Hospitals NHSFT, Gloucester
}

\subsection{6/gutjnl-2019-BSGAbstracts.484}

Introduction Upper gastrointestinal bleeding (UGIB) is a common life-threatening emergency. Gastroenterologists are typically expected to be competent in delivering endotherapy for UGIB, with the Certificate of Completion of Training (CCT) often heralding the onset of participation in on-call UGIB rotas. We aimed to analyse the volume of haemostasis experience recorded by gastroenterology CCT holders on the JAG Endoscopy Training System (JETS) e-Portfolio.

Methods In this retrospective UK-wide study, gastroenterologists awarded CCT between April 2014-April 2017 were identified from the specialist register. Credentials were crossreferenced with JETS to retrieve UGIB endotherapy experience prior to CCT. Subjects without e-portfolio involvement or those not identified on cross-referencing were excluded. Sensitivity analyses were undertaken using the lifetime gastroscopy count to evaluate validity of JETS data. Haemostasis experience was measured only for JETS-supported modalities and collated according to variceal and non-variceal therapies. The outcome measured was the number of recorded procedures requiring haemostasis, e.g. a procedure in which 3 clips were applied was considered as 1 procedure. Comparisons of continuous variables were made using Mann-Whitney (2 groups) and Kruskal-Wallis tests ( $>2$ groups).

Results Over the 3-year study period, 241 gastroenterologists were awarded CCT. After exclusions $(\mathrm{N}=9), 232$ were included for analysis. Sensitivity analysis revealed a median lifetime gastroscopy count of 854 (IQR 60-214), without variation over the three years $(\mathrm{P}=0.817)$, attesting to data integrity. A total of 12,932 endotherapy procedures for UGIB were recorded, corresponding to a median of 42 (IQR 2-1) per gastroenterologist. Exposure to non-variceal modalities (median 28, IQR 1-2) was more frequent than variceal therapies (median 11, IQR -2; $\mathrm{P}<0.001$ ). By modality (Abstract PWE113 Figure 1), adrenaline injection (median 12, IQR -3) and variceal band ligation (median 10, IQR -0) were most commonly recorded, whilst sclerotherapy experience was rare (median 0, IQR -). Exposure to UGIB haemostasis did not differ by year of CCT $(\mathrm{P}=0.130)$. However, there was significant variation by deanery $(\mathrm{P}<0.001)$, with medians of preCCT endotherapy procedures ranging from 1-26.

Conclusion Based on JETS data, exposure to UGIB endotherapy prior to CCT appears to vary between gastroenterologists, by training deanery and by procedural modality. Implementation of standardised UGIB hands-on training courses and certification may help to support and quality assure training in endotherapy.

\section{PWE-114 UPPER GI HAEMOSTASIS COURSE IMPROVES DELEGATE CONFIDENCE IN THEORETICAL AND PRACTICAL ASPECTS OF HAEMOSTASIS MANAGEMENT}

${ }^{1,2}{ }^{2}$ Keith Siau* ${ }^{*}$ Waqas Fazal, ${ }^{4,5}$ Mo Thoufeeq, ${ }^{3}$ Brian C McKaig, ${ }^{6}$ Adrian Stanley, ${ }^{4,6}$ Allan J Morris, ${ }^{3,4}$ Aravinth Murugananthan. ${ }^{1} \mathrm{JAG}$, London; ${ }^{2}$ University of Birmingham; ${ }^{3} \mathrm{New}$ Cross Hospital, Wolverhampton; ${ }^{4}$ BSG Endoscopy Quality Improvement Programme (EQIP), London; ${ }^{5}$ Sheffield Hospitals NHSFT; ${ }^{6}$ Glasgow Royal Infirmary, Glasgow

\subsection{6/gutjnl-2019-BSGAbstracts.485}

Introduction It is recognised that training in the endoscopic management of upper gastrointestinal bleeding (UGIB) is not delivered in a standardised form in gastroenterology training programmes. A standardised Upper GI Haemostasis course was developed as part of the BSG EQIP initiative in conjunction with JAG.

Methods Following pilot courses at the West of Scotland Endoscopy Training Centre, 3 one-day industry-subsidised haemostasis courses were run at 2 sites (West Midlands Endoscopy Training Centre, Sheffield Endoscopy Teaching Centre) between July-October 2018. The programme included lecture- 
based components on risk assessment, pre-endoscopic management, management of variceal, non-variceal and atypical UGIB, role of interventional radiology and surgery, report writing and rebleed plan. In addition, hands-on model training was delivered via porcine or plastic models covering adrenaline injection, thermocoagulation, clip placement, variceal banding, haemostatic powder and Sengstaken tube placement. Feedback questionnaires were offered to trainees to provide self-assessed pre and post course ratings in knowledge, skills and behaviours relevant to UGIB. Pairwise comparisons were made using Wilcoxon rank tests.

Results The haemostasis courses were attended by 27 trainees who varied in seniority between ST-. 25 had JAG certification in UGI endoscopy with an average lifetime procedure count of 553. Feedback datasheets were returned by 22 trainees. Following the course, significant improvements were reported in knowledge-based, hands-on skills and behavioural elements, and in the outcome of being "confident in independently managing UGIB" (table 1).

Conclusions Delegate confidence in understanding and delivering key aspects of management of UGIB haemostasis improved significantly with this one-day course. Integrating the course to form a part of mandatory registrar training may help to improve management of this patient cohort within the UK.

\begin{tabular}{|c|c|c|c|}
\hline \multirow[t]{2}{*}{ Course objective } & \multicolumn{2}{|c|}{$\begin{array}{l}\text { Median score } \\
\text { (range) }\end{array}$} & \multirow[t]{2}{*}{$p$-value } \\
\hline & $\begin{array}{l}\text { Pre- } \\
\text { course }\end{array}$ & $\begin{array}{l}\text { Post- } \\
\text { course }\end{array}$ & \\
\hline \multicolumn{4}{|l|}{ Knowledge } \\
\hline Risk stratification systems & $8(-0)$ & $9(-0)$ & $<0.001$ \\
\hline Medical management & $9(-0)$ & $9(-0)$ & 0.003 \\
\hline Interventional radiology and surgery & $7.5(-)$ & $9(-0)$ & $<0.001$ \\
\hline \multicolumn{4}{|l|}{ Hands-on skills } \\
\hline Adrenaline infiltration & $7(-)$ & $9(-0)$ & $<0.001$ \\
\hline Clip placement & $7(-)$ & $9(-0)$ & $<0.001$ \\
\hline Variceal banding & $8(-)$ & $9(-0)$ & $<0.001$ \\
\hline Thermal therapy & $7.5(-)$ & $9(-0)$ & $<0.001$ \\
\hline Haemostatic powder & $6(-)$ & $9(-0)$ & $<0.001$ \\
\hline Sengstaken tube placement & $6(-0)$ & $9(-0)$ & $<0.001$ \\
\hline \multicolumn{4}{|l|}{ Behaviours } \\
\hline $\begin{array}{l}\text { Appropriate verbal instructions when applying } \\
\text { haemostasis }\end{array}$ & $7(-)$ & $9(-0)$ & $<0.001$ \\
\hline Formulate rebleed plan & $8(-0)$ & $9(-0)$ & 0.003 \\
\hline Write an endoscopy report & $8(-0)$ & $9(-0)$ & 0.003 \\
\hline Be confident in independently managing UGIB & $6(-0)$ & $9(-0)$ & $<0.001$ \\
\hline
\end{tabular}

